\title{
Soil regeneration increases crop nutrients, antioxidants and adaptive responses
}

\begin{abstract}
Since 1981, the Rodale Farming Systems Trial (RFST) differentiated organic (org) from conventional (con) farming systems showing that org systems can have a transformative potential to increase soil quality. On the other hand, throughout the RFST history, con system never increased soil organic carbon (SOC) nor soil nitrogen, (SON). During the first 5 years, org systems were increased significantly $(\mathrm{p}=0.05)$ for SOC and SON. Organic farming systems do not employ org restricted inputs i.e. synthetic fertilizers and pesticides instead they relied on biologically based inputs such as cover crops, extended legume rotation and organic amendment. Conventional system used recommended fertilizer and herbicide without biological based inputs. Both Org systems, significantly increased both SOC and SON but were not statistically different from each other. Increased SOC and SON opened a research venue supporting testing hypotheses of how soil improvement can affect i) crop nutrition ii) disease reactions and iii) adaptability. Unique org and con system legacies allowed effective SOC/SON differentiations and comparison. Different soil levels were compared under the same location and same genotypes eliminated confounding factors to better evaluate the effect of the differentiated soil condition. Over 22 plus years of systematic trial conventional maize and soybean farming failed to yield any statistical increase in either soil carbon or nitrogen from their original values SOC 1.8 to $2.0 \% \mathrm{SON}$ $0.28(\mathrm{p}=0.05 \mathrm{~ns})$; on the other hand, the organic farming legacies showed statistically significant with both SOC and SON increased ( $\mathrm{p}=0.05$ ) (soil carbon 2.3 to $2.6 \%$ and soil nitrogen 0.33 to $0.35 \%$ ). Oats Avena sativa L. Ogle, 2003, maize Zea mays L. 2005 , jalapeno peppers Capsicum annum L. Campell, tomato Solanum lycopersicum and carrots Daucus sativa form sp carota 2004 and 2005 were used as soil improvement bioindicators. In addition to SOC and SON improvement, crop mineral foliar nutrients were found highly significantly improved $(\mathrm{p}=0.01)$ under the organic agricultural system legacy. Organic system mineral increase varied from $8 \%$ for potassium to $74 \%$ for boron with a mean of $32.3 \%$ organic advantage over conventional soil legacy control from foliar analysis in oats 2003 significant differences were also found in oat grain composition for mineral contents. Crop mineral contents from org differentiated soils were significantly elevated $(\mathrm{p}=0.01)$ compared to the conventional soil legacy baseline. In addition to improved SOC/SON, crop mineral nutrients in oats, the antioxidant levels of tomato fruit, carrot roots and jalapeno pepper fruits were all significantly higher in organic legacy $18 \%$ (in jalapeno pepper) to $36 \%$ organic advantage $(\mathrm{p}=0.05)$ compared to conventional system legacy. Disease assessments were tested for how soil improvement would affect crop health/adaptability. Disease were not constraining in all environment/year combinations. Nevertheless, when present and constraining, disease reactions were consistently superior under org compared to a con soil legacy. In the org legacy significant reductions in disease were found for jalapeno pepper virus complex incidence, carrot splitting percent and carrot leaf blight and tomato late blight severities. Results confirm of a positive association between soil improvement, crop nutrient content, antioxidant, plant adaptability, and negative association with disease incidence and severity. Soil organic matter appears to have wide pleiotrophic effects deserving additional study for their detailed modes of action.
\end{abstract}

Keywords: differentiated organic, conventional, history, synthetic fertilizers, disease, differentiations, pleiotrophic effects
Volume 6 Issue 2 - 2018

\author{
Paul Reed Hepperly,' Emmanual Omondi, ${ }^{2}$ \\ Rita Seidel \\ 'Department of plant pathology, The Rodale Institute, USA \\ 2Director of the Farming Systems Trial, The Rodale Institute, \\ USA
}

Correspondence: Paul Reed Hepperly, Department of plant pathology, The Rodale Institute, Kutztown, 6II Siegfriedale Road Pennsylvania, USA, Email paul.hepperly@gmail.com

Received: March 06, 2018 | Published: March 26, 2018
Abbreviations: RFST, rodale farming systems trial; SOC, soil organic carbon

\section{Introduction}

Some researchers have sounded an alarm concerning declining nutritional contents of crop products. They have suggested that nutrient and vitamin decline coincide with the growth of centralized industrialized farming methods and these are leading to the growing nutritional threat of crop, human and animal deficiencies. According to Tan et al. ${ }^{1}$ nutrient depletion is a widespread global phenomenon that threatens our global food security. These researchers suggest the deficit of current global food system is $18.7,5.1$ and $38.8 \mathrm{~kg} / \mathrm{ha} / \mathrm{yr}$ for nitrogen, phosphorus and potassium respectively. Paul Clayton ${ }^{2}$ in Health Defense (2004) cites a 1994 United States Department of Agriculture survey showing $68,55,54,37,34,32,31$ and $17 \%$ of those surveyed were lacking the daily minimum allowances of vitamins $\mathrm{E}$, A, B6, C, B4, B1, B2 and B12 respectively. Doctor Clayton concluded in his lifelong human research that multiple vitamin and mineral deficiencies are more common than not and he challenged the levels of minimal daily allowance as insufficient to optimize human health. 
The concern over crop nutritional decline has focused on the post World War 2 agriculture systems with high dependence on synthetic chemical fertilizers that substitute for organic amendment. An example of decline includes the Oklahoma State University Macgruder long term wheat plots in which soil organic matter has plummeted from almost $4 \%$ at the trial inception to about $1 \%$ after 100 years of cropping with similar results from Sandborn and Morrow plots of Univ. of Missouri and Illinois, respectively. In addition the prevalent intensive use of synthetic pesticides combine with the shortening and elimination of crop rotations, cover cropping, mixed crop and animal farming systems and use of organic amendments. Monoculture crop farming with high synthetic fertilizer and pesticide use has become the norm.

Using nitrogen isotope tracer studies, Harris et al. ${ }^{3}$ showed that legume nitrogen was better retained in the soil with less loss from the soil from a legume source compared to conventional ammoniated fertilizer. In addition substantially more nitrogen was retained in microbial biomass from the legume system.

Winchester et al. ${ }^{4}$ showed the patterns of birth defects in Indiana fluctuated according to nitrates known to stimulate oxidant activity and atrazine a known pseudo-estrogen. Levels of nitrate and atrazine in water in Indiana fluctuated seasonally according to maize production practices. The applications of y atrazine herbicide and ammoniated fertilizer applications are targeted in maize planting season. Conscious dependence on more uniform genetics and concentration of intensive use of synthetic fertilizers and pesticides has been called green revolution agriculture. Some researchers suggest these practices are derailing natural cycling of nutrients and curtailing on-farm biodiversity. In organic farming biological diversity is treasured for its ability to promote a healthy beneficial habitat and foster bio-control of prevalent pests.

As researchers became aware of the nutritional erosion in our crop staples, they have pondered ways to re-establish the lost nutrients. Khan et al. ${ }^{5}$ working with Morrow plots longest running land grant crop system analysis points to a disappearance of carbon and nitrogen related to prevailing agricultural practices particularly use of ammoniated fertilization but also the reduction of crop rotation and organic amendment. Ironically top soil applications of ammoniated fertilizers were identified as source of subsoil depletion of both carbon and nitrogen stocks.

Decades of well-planned documented work of the Rodale Farming Systems Trial (RFST) in Kutztown, Pennsylvania clearly demonstrated soil carbon and nitrogen have been differentiated based on conscious consistent application of either conventional or organic agricultural systems and practices. The RFST foundational hypothesis supports the ability of soil improvement to be reflected in food and health. The RFST provides an appropriate venue to test how soil improvement can influence crop nutrition and adaptability. Indeed the inception value of RFST was about $3 \%$ and organic management has elevated this to $4 \%$ plus with dramatic benefits which are especially visible under stress environments.

Organic agriculture reviewers Woese et al., ${ }^{6}$ Haliwell ${ }^{7}$ and Heaton put centralized industrialized monoculture food systems and practices as the primary suspects in the lowering crop nutrient content primary through crop genetics and fertilization practices changes. Many researchers have become concerned about this since unintended side effects of our agricultural practices may well relate to malnourishment which seems growing in both technologically advanced and developing human societies.

Among the changes in farming systems the higher nutritional intensity crops such as grain legume and legume forages have been mostly eliminated from many of our current crop rotations. These soil improving crop components have been largely replaced by higher yielding but less nutritious cereal grains which are more exhaustive of the soil resource. Under harvest removals without nutrient complete replacement intensive mining of minerals can occur. This mining of nutrients is governed by greater harvest removals of the lower quality but higher yielding preferred grains. According to our fertilizer experts incomplete nutrient replacement looms large in deteriorating soil conditions.

Removing legumes in our cropping systems can undermine biological nitrogen fixation. When synthetic nitrogen sources are applied to legumes the harvest of nitrogen from the air is atrophied. In addition to dwindling of the biological nitrogen capacity application of nitrogen as ammoniated fertilize can stimulate more rapid decay soil organic matter resulting in both lowering both carbon and nitrogen in the soil. Another deleterious result of fertilizer is its role in promoting increased soil acidity. Acidity in soils can promote nutrient losses, soil aging and toxicity from manganese, aluminum and iron can be stimulated by the fertilization practices. In contrast the RFST depends on legumes as crops and cover crops to increase and maintain soil quality without any synthetic fertilizer or pesticide applications.

Donald R Davis et al., ${ }^{9}$ a research associate with the Biochemical Institute at the University of Texas, Austin, analyzed data gathered by the USDA in 1950 and 1999 on the nutrient content of 43 fruit and vegetable crops finding that six out of 13 nutrients had significant declines in these crops over the 50-year period (the seven other nutrients showed no significant changes). Three minerals, phosphorous, iron and calcium, declined between 9 percent and 16 percent. Protein declined 6 percent. Riboflavin declined 38 percent and ascorbic acid (a precursor of vitamin C) declined 15 percent.., 10

Since 1981, the Rodale Institute Farming system trial directly compared organic and conventional maize and soybean production systems. The Rodale Institute motto Healthy Soil=Healthy Food=Healthy People suggests that soil improvement will have critical influence for the positive outcomes of our food system. The long term field experiment of the Rodale Institute address this hypothesis by utilizing scientific questions answered through long term yield experimentation utilizing long term large plot randomized replicated trials which are statistically analyzed and evaluated. Through these trials, the significant soil improvement engendered by organic soil management approaches has been clearly demonstrated and confirmed.

Of key interest has been significant increases in soil carbon and nitrogen which have been under attack under many conventional agriculture approaches as in Morrow, Sanborn and Macgruder plots $\mathbf{s}^{5,11}$ or University of Illinois, Missouri and Oklahoma State, respectively. These plots show a bath tub disappearance of soil organic matter and nitrogen in cultivated agriculture system based on monocultures. In the Macgruder plots a plummeting of soil organic matter from 4 to $1 \%$ is a good example of soil organic matter depletion. In contrast while Rodale soil organic matter was about $3 \%$ originally by the time 
of these studies the organic matter had become higher exceeding $4 \%$ under the organic systems of management rather than staying at about $3 \%$ as the conventional management system.

Beside the Farming Systems Trial, the Compost Utilization Trial illustrated the more conclusive soil carbon and nitrogen improvements with compost and the improvement in crop nutrient content and yields also using organic and conventional production practice comparisons. ${ }^{12,13}$ The results of these trials clearly demonstrate potential for org systems of crop management for soil improvement. Lotter et al. ${ }^{14}$ point to ability of soil improvement through organic systems to improve reaction to drought stress. Ryan et al. ${ }^{15}$ show that maize and soybean weed competition is significantly diminished in the improved soil in the RFST.

In the Farming System Trial after a 3 year transition period the organic systems were fully competitive with conventional agriculture for yield. The legume based farming systems with organic amendment proved to increase soil organic carbon and nitrogen resulting in the diverse crop benefits. This soil improvement has been shown to consistently by reducing drought year impacts which result as the major source of year by year variability in rain-fed agriculture systems in North America. The Compost Utilization Trial shows an earlier and more conclusive ability to improve soil by applying organic amendment compared to a cover covers alone.

Soil organic matter and carbon increases are associated with concurrent crop nutrient mineral content increase, improved disease reactions and crop adaptability improvement. While modern centralized agricultural systems associate with crop nutrient decline and variability from stress continues to plague crop production systems. The conscious effort that leads to soil improvement appears to show potential to 1) reverse crop nutrient depletion and 2) improve both plant disease reaction and crop adaptability.

We believe crop response is not restricted to genotypic and environmental determinants as most frequently portrayed. Rather the soil improvement plays a much more determinant role than most conventionally focused researchers suppose. We suggest as these hypotheses will continue to prove the wisdom of soil focus that should be given more prominent consideration for its critical role in nourishing and feeding our current and future generations.

In this contribution, we not only revisit the fundamental questions of our potential to manage to improve soil quality but also we continue to look at soil improvement strategy for soil organic matter efficacy in improving crop nutrition and quality. Wander et al. ${ }^{16}$ demonstrated that in just one decade of organic transition the respiration measuring the biological activity of soil increased over 50\% compared to conventional system soil respiration. Moreover, while soil improvement improves crop adaptability as proven by Lotter et al. ${ }^{14}$ for drought response. In addition Ryan et al. ${ }^{15}$ demonstrated organic legacy had less loss than would be expected in conventional maize and soybean exposed to similar weed levels.

All of these results give growing indication of organic management influence a broad spectrum of adaptive characters. Soil improvement appears to stimulation a broad spectrum of adaptive effects including crop disease responses. Finally, Asami et al. ${ }^{17}$ point to organic management resulting in higher plant defensive metabolites which improve crop quality. We postulate that beside an organic matter influence mineral and amino acid contents that the vegetable crops exposed to improved soil and natural diseases and pests display both increased antioxidant activity which accompanies crop ability to effectively adapt to multiple stresses including disease reactions.

As we have test out soil quality effects on plant nutritive roles which transfer from the soil to the crop products we also test for the same soil based effects increasing adaptive plant metabolism including antioxidant capacity. We believe antioxidants can provide a potential partial mechanism explaining how soil improvement leads to better crop qualities and responsiveness. Since plant disease and health are well linked negative interrelationship. Information of reduced disease incidence and severity assay under improved soil condition can add to indicators for multiphase approach to evaluating the role of soil quality on crop yield, quality and response.

\section{Materials and methods}

From 1981 the Rodale Farming System Trial has comprised area 6.1 hectares. The soil is moderately well drained Comly silt loam soil with a neutral $\mathrm{pH}$ 6.8. The environment is a temperate subhumid with $1105 \mathrm{~mm}$ mean annual precipitation mostly as well distributed rains during the growing season and a mean temperature of $12.4^{\circ} \mathrm{C}$.

Main plots were the 3 cropping systems. These are the conventional control treatment which uses recommended synthetic fertilizer and herbicides according to Pennsylvania State University Cooperative Extensive Service recommendation and two organic system treatments with receive no organically restricted synthetic inputs but instead use cover crops and organic amendment and a longer rotation sequence employing wheat corn soybean with cover crops and in the case of animal manure treatment has addition of raw manure on the maize crop.

Main plots are 18 by $92 \mathrm{~m}$. Main plots are separated by $1.5 \mathrm{~m}$ to minimize any chemical drift influence organic system treatments. Subplots permit the use of common farm equipment for harvesting, planting and tillage practices. Differentiated system legacies of 22 to 25 years resulted from consistent continuous practice application were evaluated under large plot randomized replicated analyzed trials generating hypotheses testing were scientifically evaluated and statistically compared for the area of our health interest. By using RFST as the framework trials a clearly differentiated the baseline soil conditions after this transformation can then be compared using common crops and environments but compared the differentiated soils under a common environment/locale and same genetic backgrounds. By eliminating confounding factors which plague efforts to assay organic systems influences such as meta-analyses of experiments which dissimilar in many aspects. Soil organic matter importance is definitively identified because we utilize a common environment and genetic background at the same time soil legacies provide proven distinct SOC, SON and organic matter levels.

\section{Evidence for soil transformation (regeneration)}

The soil transformation in the RFST was clearly evident in the chronosequential analysis of soil carbon. In mean sense the soil carbon increase was about $1 \%$ per year from the baseline under org management. The results indicating diminishing return on the increasing soil carbon increase. The rate of Nitrogen increase was similar but at $0.5 \%$ per annum about half of carbon value. By this 
soil differentiation under the organic management is found in a profile analysis which showed that most SOC elevation for the org legacy was in the first $15 \mathrm{~cm}$ or top soil showings diminishing difference in deeper profile depths. The two organic systems are shown clearly elevated but not different from each other (Figure 1).

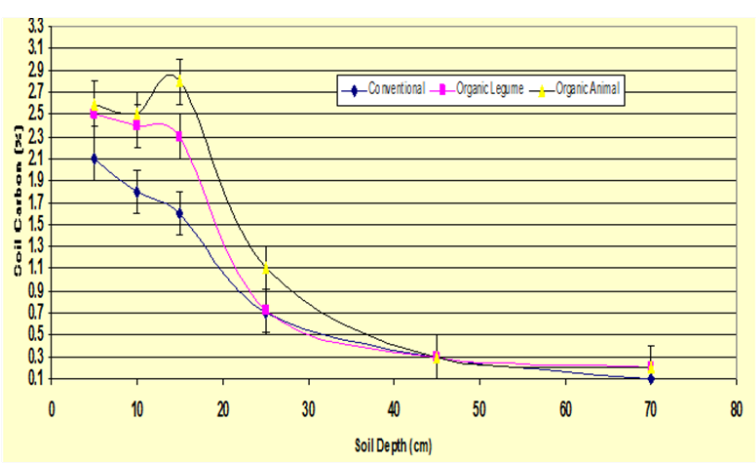

Figure I the relationship of soil carbon to soil profile Depth in organic and conventional system at the Rodale institute farming systems Trial 2006.

Mineral nutrient contents were determined by atomic spectral analysis Pennsylvania State Ag Analytical Services Laboratory, University Park, PA 16802 tel 814-863-0841 aaslb@psu.edu using ICP analysis for foliage sample and carbon and nitrogen for soil. For amino acids, stalk nitrates, crude and digestible protein plus crude fiber the Dairy One 230 Warren Road, Ithaca, NY amr@dairyone.com were employed that employ near infrared reflectance spectroscopy according to certified standard calibrated practices. For determination of ascorbic and total antioxidant capacity we used Campbell Soup, Food Analytical Laboratory in Camden, New Jersey. Antioxidants were determined in mg per 100 gram samples and the level in organic plots were divided by the control conventional plot values and then multiplied by 100 to express values in terms of advantage of organic compared to Con control. This same relative organic advantage was used for oats and maize determinations and in the case of disease incidence and severity.

In each case of org and conv comparison common genotypes were employed. The varieties of carrots jalapeno pepper and tomato were all provided by collaborating researchers at Campbell Soup Company who also collaborated in research plan and implementation. Ogle oats were selected by Rodale research and production team and the maize hybrid was suggested by Blue River Hybrids for its local superior ability to produce under organic production system. Crop adaptability assessment focused on field scoring and assaying the disease incidence and severity at the Rodale Institute Kutztown, Pennsylvania RFST using the scoring by the first author in house.

Nested plots of org and con legacies were paired in adjacent areas as paired plots. The plots were square compromising of $6.1 \mathrm{~m}$ by $6.1 \mathrm{~m}$ four rows of $76.2 \mathrm{~cm}$ row centers. Organic and con plots were replicated four times. For jalapeno pepper and tomatoes the plantings were established by transplanting one month old plants from the greenhouse $45.7 \mathrm{~cm}$ apart as the intra-row spacing as recommended by Campbell Soup Company production practices. The center two rows of plots were harvested for yield determination and sampled for quality tests. Maize plots had an intra-row direct planting separation with a 25.4 intra=row spacing, Oats were drilled in $15 \mathrm{~cm}$ drill row with $7 \mathrm{~cm}$ between plants intra drill rows. These populations are considered near optimum under the Kutztown RFST environment.

\section{Results}

\section{Oat leaf mineral differentiation 2003}

In 2003 Ogle oats were blanket planted over RFST because of the loss of organic weed control that had occurred. Oats as competitive allelopathic crop provided a mechanism for reducing weed infestations which had proliferated under organic management and provided highly effective. We took advantage to conduct leaf foliage mineral analysis assess if the soil improvement were affecting the mineral nutrition. We were astounded on the significance and magnitude that soil organic matter was conferring on mineral nutrient content. This indicated a very significant soil legacy effect which was noted in mineral nutrients of the foliar. The effect which appeared to vary among the nutrients had a mean value of $32.3 \%$. The increase of soil carbon and nitrogen were about 1 and $0.5 \%$ per annum for carbon and nitrogen, respectively from baseline values (Figure 2).

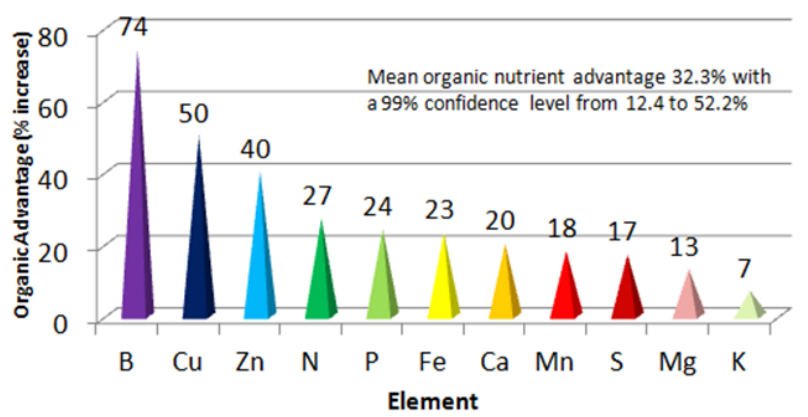

Figure 2 Organic foliar leaf nutrient enhancement expressed percentage organic soil system advantage. The foliar tissue analysis in uniform trials comparing organic and conventional legacies in Ogle oats Rodale Farming System Trial 2003, Kutztown, PA with Penn Sta.

From 2003 to 2005 the unique Rodale Farming System Trial was employed to test the relationship of the demonstrated soil improvements from the organic system employment to the reactions of food crops in terms 1) mineral content 2) antioxidant vitamins 3) essential amino acids fiber and nitrogen dynamic under heavy rainfall 4) reaction to prevalent diseases (Figure 3).

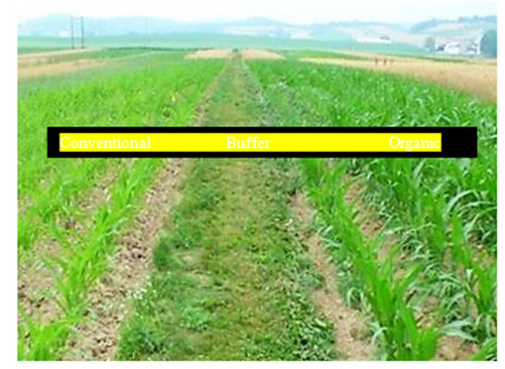

Figure 3 Maize Grain Quality Differentiation 2004 Extreme wet year. 


\section{Maize grain quality differentiation 2004 extreme wet year}

In maize under the extreme high moisture year 2004 nitrogen deficiency (chlorosis) was visible in the above photo on your left in the conventional legacy. The main plot showing no obvious yellowing or chlorosis was the organic legacy. July precipitation was $20.3 \mathrm{~cm}$ double the mean value of about $10 \mathrm{~cm}$. Under supersaturated environment the development of anaerobic soil condition lead to denitrification. This explains the prevalent chlorosis in the con plots but not the org systems. This supposition was supported by nitrate analysis of corn stalks at maturity the lower yield in conventional legacy as well as decreased crude and available protein lysine and methionine amino acids. Maize grain yield than the organic $7,902 \mathrm{~kg} / \mathrm{ha}$ compared to $6,844 \mathrm{~kg} / \mathrm{ha}(\mathrm{p}=0.05)$ while analysis of stalks confirmed the much higher nitrate value of organic legacy from conserved and increased soil nitrogen crop under the extreme conditions. Content improvement from the org compared to con be found for non digestible fiber, crude and available protein and lysine and methionine essential amino acids (Figure 4).

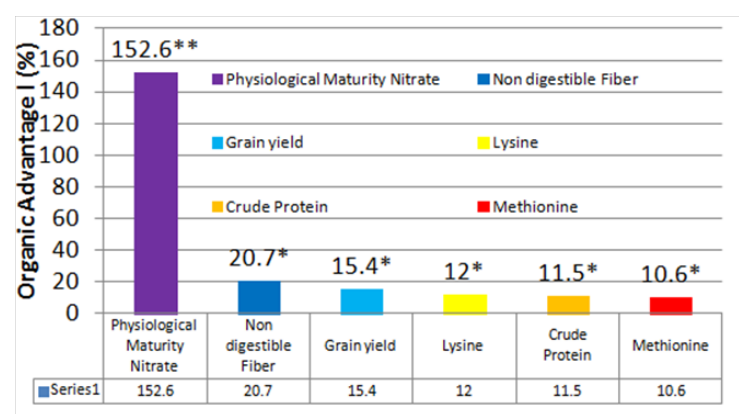

Figure 4 Percentage organic advantage for maize Zea mays L. quality criteria in an extreme high moisture year showing chlorosis. Organic advantage expressed in uniform trial in Rodale Farming System Trial compares organic to conventional legacy Kutztown .

These maize results attest to the power of the organic management legacy under the stress environment this time excessive precipitation. The lysimeter measures from RFST indicate the increase percolation of soil organic improved soils which increase both water and aeration. Of interest in this situation is that high stem nitrate and increased yield crude protein and essential amino acids are reflective of nitrogen conservation and use based on a more aerobic environment in the org soil. Transformed soil seems not favor bacterial use nitrate as their oxygen source which would prevail under an aerobically constrained environment in poor textured low organic matter soil which was witnessed in this test.

Lotter et al. ${ }^{14}$ has found superior reactions of the organic systems in the RFST under drought stress years. Combined with maize results in the overly wet year puts to broad spectrum of issues influenced favorably under improved SOC. Another indication of broad influence of the soil organic matter influence is Ryan et al. ${ }^{15,18}$ who also in RFST shows as organic practices impact the soil condition decreasing maize and soybean crop losses from weed competition significantly. Since we see dry, weeds and wet stresses responding better than con management it would suggest general stress tolerance and nutrition is favored under organic legacy.

\section{Antioxidant differentiation 2005}

The advantage of organic legacy for total antioxidant capacity was determined by the certified laboratory facilities of Campbell Soup Company. The increased content in organic soil legacy was greatest in tomato (36.3\% advantage) and least in jalapeno pepper $(18.1 \%$ advantage) while carrots were intermediate (28.9) (Figure 5).

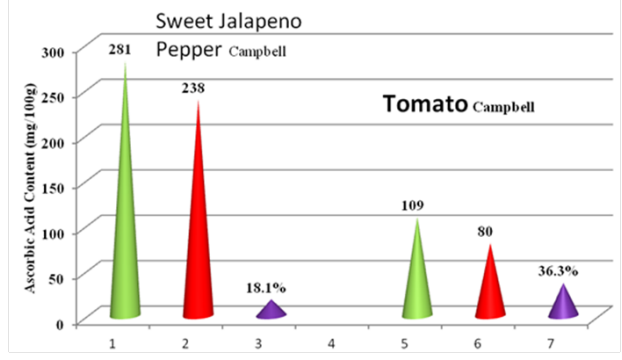

Figure 5 Ascorbic acid organic (green) conventional (red) and percent organic advantage (violet) from Rodale Farming System Trial 2005 Kutztown, Pennsylvania.

While all the vegetables showed significant increased in antioxidant capacity the biggest effect was in tomato the lowest in total antioxidants jalapeno with is highest showed the least organic advantage. This is reverse of their natural antioxidant ranking with jalapeno having the most and tomato having the least. Mean organic legacy advantage for tomato ascorbic acid, carrot total antioxidants and jalapeno ascorbic acid were $36.3,28.8$ and $18.1 \%$, respectively. The grand mean of this organic antioxidant advantage was $27.7 \%$ while $15.2 \%$ to $40.2 \%$ constituted the $95 \%$ confidence level of the mean.

These results are consistent with Asami et al. ${ }^{17}$ showing higher defensive compounds in the organically produced produce and the magnitude of the effect was similar to their report.

\section{Disease incidence and severity differentiation 2004 and 2005}

Another area selected for investigating the possible soil legacy effects on plant disease reactions. Crop disease reactions were determined by scoring disease incidence and rating severity. Disease epidemics were not found in each year but when they were we were able to see significant reduction of diseases incidence and severity (Figure 6).

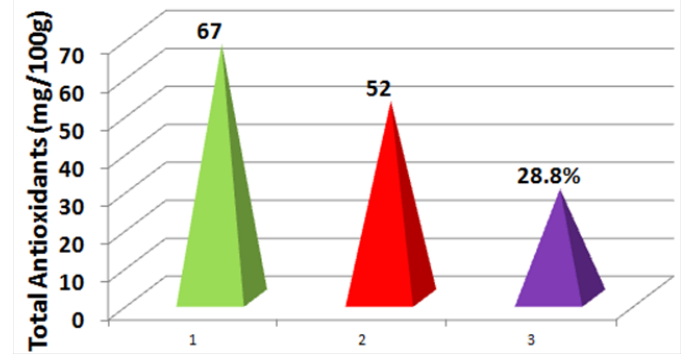

Figure 6 Total carrot antioxidants $(\mathrm{mg} / \mathrm{l00g})$ green organic legacy (green) conventional (red)and organic percent advantage (violet) from Rodale FST Kutztown, PA 2005. 
Disease effect was most prominent in carrots in 2005 when organic soils led to significantly higher yield as the reduction of carrot splitting was significantly reduced. In both 2004 and 2005 foliar blight by Alternaria dauci were significantly reduced on the org soil legacy.

Sizable significant $(p=0.05)$ and highly significant $(p=0,01)$ enhancement of disease reactions and yield responses were found in constrained environment from the improved soil in organic legacy (Figure 7). The ability to determine these differences are mostly expressed in disease epidemic environments otherwise these may go unperceived.

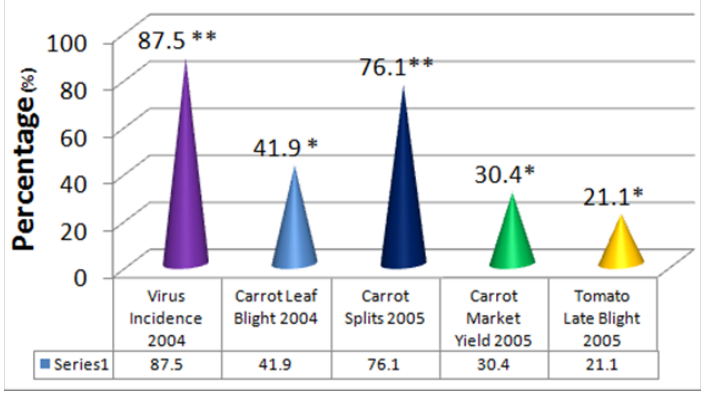

Figure 7 Significant reductions of pepper poty virus incidence, carrot leaf blight Alternaria dauci (J. G. Kuhn) J.W. Grove and Skolko severity, carrot splits and tomato late blight Phythopthora infestans (Mont.) de Bary severity and improved carrot yield as a $\mathrm{f}$.

\section{High yield potential throughout trials}

2003 Oat yields were good much higher than county means. The mean yields of both organic and conventional systems were about $3,500 \mathrm{~kg} / \mathrm{ha}$ for oat grain and not significant between the legacies. Yield was significantly higher than county mean oat yielded of about $2,300 \mathrm{~kg} / \mathrm{ha}$. In 2004 tomato late blight caused a crop failure for both organic and conventional soils invalidating yield comparisons. The heavy summer precipitation produced an extremely favorable environment for late blight in tomato. In 2004 and 2005 Jalapeno peppers yields were 26,000 to $43,000 \mathrm{~kg}$ /ha with no significant yield difference between the organic and conventional soil legacies. In 2005 carrot organic legacy yield was $18,000 \mathrm{~kg} / \mathrm{ha}$ compared to $13,800 \mathrm{p}$ $(0.05)$. This superior organic carrot yield was related to reduce splitting in organic carrots while significantly high incidence of splitting was found in conventional soil plots resulting in the significantly reducing marketable yield of con carrots. Leaf blight from Alternaria dauci was reduced significantly in the organic system legacy this would support who reported higher nutrients from soil fertilization reduced plant disease severity. Our studies show higher nutrient levels associated with organic legacy.

\section{Discussion}

Since World War 2, information from the United States ${ }^{9,19}$ and United Kingdom ${ }^{20-22}$ suggest a declining nutrient value of fruits, vegetables and cereal grains. In Great Britain, for example, the mineral content of fruits and vegetables between 1930 and 1980 shows marked decreases in nutrient density from food composition tables from government sources. The British study found significantly lowered vegetable levels of calcium, magnesium, copper and sodium were found and in fruits magnesium, iron, copper and potassium were lower. The report concludes that the declines indicate "that a nutritional problem associated with the quality of food has developed over those 50 years." Which coincides to the post World War 2 era. In Finland ${ }^{23}$ has also shown continuing nutrient decline similar to the results in United States and United Kingdom.

According to Welch et al. ${ }^{24}$ over 3 billion people around the globe are malnourished having insufficiency in mineral elements and vitamins. Fan ${ }^{25}$ document the decline of wheat in 160 years of archived samples concurring with Garvin, et al. 2006 who showed a deterioration of selenium zinc and iron content. Scott et al. ${ }^{26}$ stress modern day maize varieties have higher yield but lower protein and essential amino acids such as lysine, methionine and tryptophan.

It appears that part of our global nutritional challenge is that while people are consuming more cereals these are of lower quality. In addition as consumers eat fewer vegetables and fruits these are also of eating lower quality fruits and vegetables. Since this has been happening as fertilizer inputs have increased it challenges the green revolution paradigm that fertilizer is a part of a global nutritional solution. Rather results suggest current practices, art, and science need to be challenged and possibly revised. Our current practices appear to part of a largely ignored unseen problem with a large degree of denial based on vested interest of the input providers.

Despite a minority appreciation of the connection or our agricultural practices and their nutritional outcomes, the intrinsic value of soil improvement is awaiting recognition acknowledgement and confirmation by large audience researchers, farmers, extensionists, policymakers, and the consumer.

Davis lamented concerning the continuing decline of fruit, grain and vegetable nutrient content and stressed a continuing need to address this issue and reverse the prevailing nutrient decline. Welch et al. ${ }^{24}$ stressed the need to addressing malnutrition holistically through the food system as a whole. In this mostly bleak panorama, the shining light may well be the ability of our agricultural practices to improve our soils rather than a tendency to continue to deplete them. This change in understanding will be bolstered as soil data are confirmed for their relationship with crop nutrient content on which we report. In these regards the Rodale Farming System Trial provides a unique tool for knowledge insight and points to solutions of the nutrient depletion issue.

While most investigators have strongly defined crop issues for their genetic or environmental roots, soil quality influences on crop quality and adaptation are less studied. This lack of study is especially marked in conventional synthetic input proponent community. For vested parties the view that inputs are part of issues and constraints is not very digestible.

Indeed is there a growing informational basis for suggesting soil conditions and quality which are not fully appreciated and are soil effects not fully understood for their large influence on crop nutritional status? It is interesting that when concerned communities approached the United States Department of Agriculture the Department through petitioning the Secretary of Agriculture under President Obama the department offered no response to their queries.

Organic researchers have been the most avid in following this thread of soil crop nutrition connection. Just as animal responses have been clearly linked to nutrition, the influence of crop disease reaction and adaptation capacity deserves more intense consideration for a soil 
nutritional focus in their remediation. It is interesting that veterinary and dentists often see the more benefit of nutritional approaches based as the economics become to forefront by avoiding costly surgeries.

Of particular interest from our results is that metabolic stimulation of defensive mechanism under stress condition such as growth regulation stimulation improved defensive reactions through secondary metabolites are available. The ground breaking work of Asami et al. ${ }^{17}$ and Mitchell et al. ${ }^{27}$ stress the importance of antioxidants and defensive plant metabolites as advantageous and stimulated in organic agriculture production systems. In their analysis soil influence was not considered with response being postulated related to withdrawing chemical protection and therefore, not eliciting greater biochemical responses to pests while not considering the effect of soil transformation or regeneration as a way to stimulate positive crop response.

The vast majority of food products originate from our soil with a very small part for soil less systems. There is little information that suggests global soils are improving or even being effectively conserved as the area degraded soils is increasing around the globe has expanded notably. Considering RFST ability to demonstrate soil improvement and this association with both enriched crop nutrient status, plant adaptive responses and high yield potential continuing to overlook the importance of soil to health issues will be at our own peril and that of future generations.

Besides the effects of organic agriculture for energy environment and economics ${ }^{13}$ we may need to add the beneficial impact of regeneration of soil for crop nutritional benefits. Indeed, soil improvement appeared fundament with improved crop adaptability as is shown from reduced disease incidence under epidemic environment under improved org soils. The ability of organic systems to improve drought and weed tolerance might also be included. Organic farmers and researchers have long observed these effects yet experimentally verified confirmations have lagged also. Thus, our RFST results work to confirm long term observation of organic farmers and the proponents of organic agriculture and not to support the position that soil has minimal or no effect on crop nutrition and quality often stated by conventional agriculture interests. This nutritional influence based in the soil may be related to improved secondary metabolites such as antioxidants as well as greater minerals and essential amino acids all of which are part of nutritional basis of plant adaptability and are grounded in soil quality.

Beside the suggestion of the influence of carbon and nitrogen the biology of the RFST suggest enhanced mycorrhizal diversity and activity can be important in the transformational mechanism and results. Legume grass rotations, covers and organic amendment can stimulate mycorrhizae and rhizoidal activities. ${ }^{28,29}$ Mycorrhizae are known to extend the connection of plant roots to the soil increasing soil to root contact by hundreds to thousands of times the naked root system without mycorrhizae.

Pesticides and synthetic fertilizer nutrients have been well documented to reduce both mycorrhizae and Rhizobia symbiosis. Mulvaney et al. ${ }^{30}$ details the depletion of soil reserve in the Morrow plots that has occurred in the subsoils of Mollisols which are fertilized with ammoniated fertilizer pointing to the need to change the conventional input perspective.
Indeed the RFST design of systems ${ }^{31}$ is based on legumes covers soil organic amendment and more extended and diversified crop rotation. The wisdom of this approach is testified by marked improvement in the soil measurement and in plant adaptability and resulting nutrition. In keeping with actual results they confirm increase of soil nitrogen and carbon reserves are increasing numerous indicators of plant adaptability and crop quality which all are all linked together in the soil.

While traditionally genetics and environment are considered prime crop determinants our cropping experimental trial results shows the critical capacity of improved soil to enhance the value of our crops nutritionally which is also associated with increased plant adaptation or health which can be seen under disease epidemic conditions. Except for some ardent soil organic enthusiasts we continue to see a vast gap in the appreciation of the value of soil value as a means we have to optimizing our food systems for mankind's greatest benefit.

Considering the conclusive dataset which have been revealed for soil improvement and its multifaceted importance, soil improvement deserves much more follow though than it has been given to date by vast majority of our farmers, extensionists researchers and policy maker communities and consumers. ${ }^{31}$ Kimetu et al. ${ }^{32}$ used the continuous cropping chromo-sequences to engender severe soil degradation in Kenya then showed Mexican Sunflower and biochar amendments reverse severe crop yield declines on the continuously cropped soils. ${ }^{33}$ All these results suggest a high quality and yield agriculture may well demand taking organic technologies and systems much more seriously than many conventional researchers have done to date. In particular the organic matter content and management appears to be particularly determinant even though it is not usually considered as such.

\section{Acknowledgement}

None.

\section{Conflict of interest}

The author declared there in none of conflicts.

\section{References}

1. Tan ZX, Lal R, Wiebe KD. Global soil nutrient depletion and yield reduction. J Sust Agr. 2005;26(1):123-153.

2. Clayton Paul. Health Defense. Accelerated Learning Systems. London. 2004. $440 \mathrm{p}$.

3. Harris G, Hesterman O, Paul E, et al. Fate of legume and fertilizer nitrogen-15 in long term cropping system experiment. Agron J. 1994;(86):910-915.

4. Winchester PD, Huskins J, Ying J. Agrichemicals in surface water and birth defects in the United States. Acta Paediatr. 2009;98(4):664-669.

5. Khan SA, Mulvaney RL, Ellsworth TR, et al. The myth of nitrogen fertilization for carbon sequestration. $J$ Environ Qual. 2007;36(6):1821-1832.

6. Woese $\mathrm{K}$, Lange D, Boess C, et al. A comparison of organically and conventionally grown foods results of a revision of relevant literature. $J$ Food Agr. 1997;74(3):281-283.

7. Halweil Brian. Still no free lunch: nutrient leves in United States food supply eroded by pursuit of high yields. Organic Center. 2007. 48 p. 
8. Heaton Shane. Organic farming food quality and human health: a review of the evidence. Soil Association. UK: Bristol. 2001. 36 p.

9. Davis DR, Epp MD, Riordan HD. Changes in USDA Food Composition Data for 43 Garden Crops, 1950-1999. J Am Coll Nutr. 2006;23(6):669-682.

10. Davis DR. Declining fruit and vegetable nutrient composition: what is the evidence? Hort Science. 2009;44(1):15-19.

11. Girma K, Holtz SI, Arnall RR, et al. The Magruder Plots: Untangling the puzzle. Agron J. 2007;(99):1191-1198.

12. Hepperly P, Lotter D, Ziegler Ulsh C, et al. Compost, Manure and Synthetic Fertilizer Influences Crop Yields, Soil Properties, Nitrate Leaching and Crop Nutrient Content. Compost Science and Utilization. 2009; 17(2):117-126

13. Pimentel D, Hepperly P, Hanson J, et al. Environmental, energetic and economic comparisons of organic and conventional farming systems. Bio Science. 2005;55(7):573-582.

14. Lotter DW, Seidel R, Liebhart W. The performance of organic and conventional cropping systems in an extreme climate year. American Journal of Alternative Agriculture. 2003;18(3):146-154.

15. Ryan MR, Mortensen DA, Bastiian J, et al. Elucidating the apparent maize tolerance to weed competition in long term organically managed systems. Weed Research. 2010;(50):25-31.

16. Wander M, Traina S, Stinner B, et al. Organic and conventional management effect on biologically active soil organic matter pools. Soil Sci Soc Amer J. 1994;58(4):1130-1134.

17. Asami DK, Hong YJ, Barrett DM, et al. Comparison of the total phenolic and ascorbic acid content of freeze-dried and air-dried marionberry, strawberry, and corn using conventional, organic, and sustainable agricultural practices. Journal of Agricultural and Food Chemistry. 2003;51(5):1237-1241.

18. Ryan M, Smith R, Mortensen D, et al. Weed crop competition relationships differ between organic and conventional cropping systems. Weed Research. 2009(;4)9:572-580.

19. Worthington Virginia. Nutritional quality of organic versus conventional fruits, vegetables, and grains. J Altern Complement Med. 2001;7(2):161-173.

20. McCance RA, Widdowson EM. The chemical compostion of foods Medical Research Council Special Report Series No. 235. 2nd ed. London: His Majesty's Stationery Office. 1946. 156 p.
21. Mccance RA, Widdowson EM. Composition of Foods. 3rd ed. Medical Research Council Special Report Series No. 297. London: Her Majesty's Stationery Office. 1960.

22. Mayer AM. Historical change in fruit and vegetables. Brit Food J. 1997;99(6):207-217.

23. Ekholam P, Reinivuo H, Attila P, et al. Changes in the mineral and trace element contents of cereals, fruits, and vegetables in Finland. $J$ Food Comp Anal. 2007;20(6):487-495.

24. Welch RM, Robin Graham. A new paradigm for world agriculture meeting human needs productive sustainable nutritious. Field Crop Research. 1999;60(1-2):1-10.

25. Fan MS, Zhao FJ, Fairweather-Tait SJ, et al. Evidence of decreasing mineral density in wheat over the last 160 years. $J$ Trace Elements Med Biol. 2008;22(4):315-324.

26. Scott MP, Edwards JW, Cell CP, et al. Grain composition and amino acid content in maize cultivars representing 80 years of commercial varieties. Maydica. 2006;51(2):417-423.

27. Mitchell A, Chassy A. Antioxidants and nutrition quality of organic agriculture. Amer J Clinical Nutr. 2004;(76):560-568.

28. Douds D, Janke R, Peters S. VAM fungus spore population colonization of roots of maize and soybean under conventional and low input sustainable agriculture. Agriculture Ecology and Environment. $1993 ; 43(3-4): 325-335$

29. Galvez L, Douds D, Drinkwater L, et al. Effect of tillage and farming system on vam fungi mycorrhizae and nutrient uptake of maize. Plant Soil. 2001;228(2):299-308.

30. Mulvaney RI, Khan SA, Ellsworth TR. Synthetic nitrogen fertilizer: a global dilemma for sustainable cereal production. J Environ Qual. 2012;38(6):2295-2314

31. Farnham MW, Keinath AP, Grusak MA. Mineral concentration of broccoli florets in relation to year of release. Crop Sci. 2010;51(6):2721-2727.

32. Kimetu JM, Lehmann J, Ngoze SO, et al. Reversibility of soil production decline with organic matter of different with organic matter of different quality along a degradation gradient. Ecosystem. 2008;(11):726-739.

33. Garvin DF, Welch RM, Finley JW. Historical shift in seed mineral micronutrient concentration of United States hard red winter wheat. $\mathrm{J} \mathrm{Sci}$ Food Agr. 2006;(86):2213-2220. 